\title{
Cerebral Venous Wall Diseases: The Other Side of the Picture
}

$\mathbf{T}$ raditionally, the attention of the neurovascular community has been on the arterial system. Even when looking at venous cerebral pathology, most attention has to date focused on cerebral venous thrombosis. More recently, parallel developments in both medical imaging and neurointerventional techniques have focused more attention on the cerebral veins and venous sinuses. Our knowledge of venous and arteriovenous physiology and pathology is improving significantly, thanks to the anatomic and physiologic data we are gleaning from both modern MR imaging techniques and venous endovascular techniques. Despite this, however, our knowledge of the cerebral venous physiology is still significantly lacking compared with our grasp of the arterial system, meaning that this represents a fascinating research avenue.

The discovery in the past decade of the glymphatic system has cast new light on CSF clearance pathways in the brain and raised intriguing new possibilities regarding diseases that have thus far been called idiopathic. ${ }^{1-3}$ In recent years, many studies have demonstrated that "idiopathic" stenoses could affect the dural sinuses and can be associated with several clinical symptoms such as pulsatile tinnitus (PT) or idiopathic intracranial hypertension (IIH). ${ }^{4-6}$ This alone represents a major paradigm shift in neurovascular diseases because the concept of "cerebral venous wall disease" has hitherto not been well-addressed. Unlike the arteries and veins, the dural sinuses are not surrounded by their own "wall." Instead, the venous blood of the dural sinuses is surrounded by the dura mater. This thick envelope surrounds the brain, the CSF spaces, and the venous blood. Far from being an inert fibrous membrane, however, the dura is now recognized to be a metabolically and immunologically active membrane, with arteries, veins, and lymphatics. ${ }^{7,8}$ It also appears to be actively involved in regulation of CSF clearance. ${ }^{9,10}$

Given these anatomic observations, the mechanisms of formation of venous sinuses are probably more complex than previously suspected. ${ }^{11}$ Although the relationships between intracranial pressure (ICP) and transverse sinus stenoses (TSSs) has long been a matter of debate, ${ }^{12-14}$ we now realize that these stenoses may play an intrinsic role in maintaining and/or triggering the so-called vicious circle of IIH. The effectiveness of venous sinus stent placement to relieve the symptoms related to ICP has probably been the best proof of this theory. ${ }^{15}$ Thus, TSSs lead to an increase in the cerebral venous pressure, thereby interrupting the passive resorption of CSF from the subarachnoid space to the venous blood of the dural sinuses. However, the mechanisms of formation of these TSSs are still poorly understood.

Accordingly, it is crucial that we improve our knowledge of venous sinus stenoses. With this in mind, Sundararajan et $\mathrm{al}^{16}$ provide a very good radiologic observation of patients with symptomatic TSSs. In one of the largest series published so far, they report that most patients with IIH possessed extrinsic TSSs, and most patients with PT were found to have intrinsic TSSs. Whereas an extrinsic stenosis is usually defined as a long segment of sinus stenosis without an endoluminal component, an intrinsic stenosis is usually defined as the presence of one (or several) granulation projecting into the sinus. Although the dichotomization of stenoses into these types appears to have some relevance to clinical practice and to neurointerventions, ${ }^{17}$ it is probably a crude approximation of the underlying morphology of the stenosis. Indeed, many stenoses may have both intrinsic and extrinsic components. Furthermore, some patients may have an extrinsic stenosis on one side and an intrinsic one on the other side. Despite these limitations, we believe that a continuum between extrinsic and intrinsic stenoses seems to arise over time, a supposition that is based on our clinical and radiologic observations. Although both types of TSS seem to preferentially affect overweight women, their clinical impact and morphology seem to evolve with age. ${ }^{18}$ Extrinsic stenoses are more commonly diagnosed in younger patients, and IIH is by far the most common primary clinical presentation in these patients. The severity and risk of recurrence of IIH after venous sinus stent placement are significantly higher in these patients than in older patients with intrinsic stenoses. On the other hand, intrinsic stenoses are more frequently observed in older patients who present with more benign $\mathrm{IIH}$ or even with isolated pulsatile tinnitus.

Despite the limitations of this dichotomy, distinguishing between extrinsic and intrinsic stenoses appears to be helpful in clinical practice; it may represent the best we have for now. But outside of these practical considerations, these observations should prompt us to keep exploring the underlying pathophysiological mechanisms of TSS and to improve our knowledge of the venous physiology and better understand how it relates to CSF circulation. We now have to go on the other side of the neurovascular picture, keeping in mind that "All photos are accurate. None of them is the truth" (Richard Avedon). 


\section{REFERENCES}

1. Rasmussen MK, Mestre $H$, Nedergaard M. The glymphatic pathway in neurological disorders. Lancet Neurol 2018;17:1016-24 CrossRef Medline

2. Iliff JJ, Goldman SA, Nedergaard M. Implications of the discovery of brain lymphatic pathways. Lancet Neurol 2015;14:977-79 CrossRef Medline

3. Iliff JJ, Wang M, Zeppenfeld DM, et al. Cerebral arterial pulsation drives paravascular CSF-interstitial fluid exchange in the murine brain. J Neurosci 2013;33:18190-99 CrossRef Medline

4. Farb RI, Vanek I, Scott JN, et al. Idiopathic intracranial hypertension: the prevalence and morphology of sinovenous stenosis. Neurology 2003;60:1418-24 CrossRef Medline

5. Lenck S, Labeyrie MA, Vallee F, et al. Stent placement for disabling pulsatile tinnitus caused by a lateral sinus stenosis: a retrospective study. Oper Neurosurg (Hagerstown) 2017;13:560-65 CrossRef Medline

6. Higgins JN, Cousins C, Owler BK, et al. Idiopathic intracranial hypertension: 12 cases treated by venous sinus stenting. J Neurol Neurosurg Psychiatry 2003;74:1662-66 CrossRef Medline

7. Kierdorf K, Masuda T, Jordao MJC, et al. Macrophages at CNS interfaces: ontogeny and function in health and disease. Nat Rev Neurosci 2019;20:547-62 CrossRef Medline

8. Louveau A, Smirnov I, Keyes TJ, et al. Structural and functional features of central nervous system lymphatic vessels. Nature 2015;523:337-41 CrossRef Medline

9. Da Mesquita S, Louveau A, Vaccari A, et al. Functional aspects of meningeal lymphatics in ageing and Alzheimer's disease. Nature 2018;560:185-91 CrossRef Medline

10. Vinje V, Eklund A, Mardal KA, et al. Intracranial pressure elevation alters CSF clearance pathways. Fluids Barriers CNS 2020;17:29 CrossRef Medline

11. Lenck S, Radovanovic I, Nicholson P, et al. Idiopathic intracranial hypertension: The veno glymphatic connections. Neurology 2018;91:515-22 CrossRef Medline

12. Scoffings DJ, Pickard JD, Higgins JN. Resolution of transverse sinus stenoses immediately after CSF withdrawal in idiopathic intracranial hypertension. J Neurol Neurosurg Psychiatry 2007;78:911-12 CrossRef Medline

13. Bono F, Giliberto C, Mastrandrea C, et al. Transverse sinus stenoses persist after normalization of the CSF pressure in IIH. Neurology 2005;65:1090-93 CrossRef Medline

14. Chan W, Neufeld A, Maxner C, et al. Irreversibility of transverse venous sinus stenosis and optic nerve edema post-lumbar puncture in idiopathic intracranial hypertension. Can J Ophthalmol 2019;54:e5759 CrossRef Medline

15. Nicholson P, Brinjikji W, Radovanovic I, et al. Venous sinus stenting for idiopathic intracranial hypertension: a systematic review and meta-analysis. J Neurointerv Surg 2019;11:380-85 CrossRef Medline

16. Sundararajan SH, Ramos AD, Kishore V, et al. Dural sinus venous sinus stenosis: why distinguishing intrinsic versus extrinsic stenosis matters. AJNR Am J Neuroradiol 2021 in press

17. Kumpe DA, Seinfeld J, Huang X, et al. Dural sinus stenting for idiopathic intracranial hypertension: factors associated with hemodynamic failure and management with extended stenting. J Neurointerv Surg 2017;9:867-74 CrossRef Medline

18. Lenck S, Vallee F, Labeyrie MA, et al. Stenting of the lateral sinus in idiopathic intracranial hypertension according to the type of stenosis. Neurosurgery 2017;80:393-400 CrossRef Medline

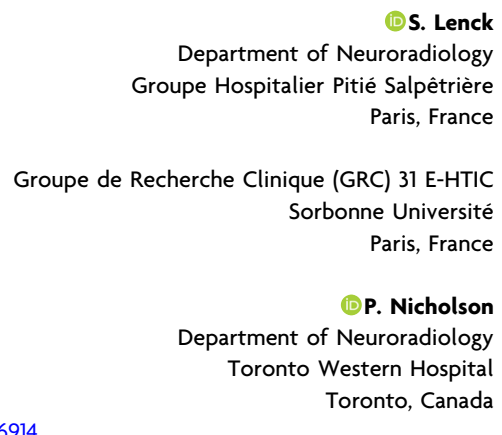

http://dx.doi.org/10.3174/ajnr.A6914 